\title{
Surface reactions of nitrogen oxide and ethylene on rhodium (111)
}

\author{
R.M. van Hardeveld, A.J.G.W. Schmidt and J.W. Niemantsverdriet ${ }^{\text {a,1 }}$ \\ Schuit Institute of Catalysis, Eindhoven University of Technology, $5600 \mathrm{MB}$, The Netherlands \\ ${ }^{\mathrm{a}}$ E-mail: tgtahn@chem.tue.nl \\ Received 17 May 1996; accepted 23 July 1996
}

\begin{abstract}
Temperature programming of $\mathrm{NO}$ and $\mathrm{C}_{2} \mathrm{H}_{4}$ coadsorbed on $\mathrm{Rh}(111)$ gives rise to the desorption of a number of gases. Where $\mathrm{H}_{2}, \mathrm{H}_{2} \mathrm{O}, \mathrm{CO}_{2}$ and $\mathrm{N}_{2}$ are the main products at low $\mathrm{C}_{2} \mathrm{H}_{4}$ coverages, significant amounts of $\mathrm{HCN}, \mathrm{CO}$ and NO evolve at higher $\mathrm{C}_{2} \mathrm{H}_{4}$ coverages. Static SIMS indicates the formation of a large supply of adsorbed $\mathrm{CN}$ species, part of which desorbs as $\mathrm{HCN}$, while the remainder decomposes and is responsible for delayed formation of $\mathrm{N}_{2}$. For the highest $\mathrm{C}_{2} \mathrm{H}_{4}$ coverages the majority of the initially adsorbed NO desorbs as HCN.
\end{abstract}

Keywords: NO reduction; TPRS; SIMS; ethylene; rhodium

\section{Introduction}

Although the reaction between $\mathrm{NO}$ and $\mathrm{CO}$ to $\mathrm{CO}_{2}$ and $\mathrm{N}_{2}$ is commonly held responsible for the removal of NO from automotive exhausts on the three-way catalyst, hydrogen and hydrocarbons make a substantial contribution to NO reduction as well [1]. Cracking of gasoline in the engine of a car is the source of $\mathrm{H}_{2}$ (estimated to account for roughly $30 \%$ of the concentration of $\mathrm{CO}$ in the exhaust) and a range of smaller hydrocarbons, among which methane, acetylene, ethylene, benzene and toluene are the most abundant ones [2]. Unsaturated hydrocarbons such as ethylene and propylene readily adsorb on the noble metals of the three-way catalyst and are a source of $\mathrm{H}$ - and $\mathrm{C}$-atoms available for reaction with e.g. the $\mathrm{O}$-atoms of dissociatively adsorbed $\mathrm{NO}$ and $\mathrm{O}_{2}$.

Several papers are available on the reduction of NO by small hydrocarbons in copper exchanged zeolites [35], but much less is known about their interaction on platinum and rhodium [6]. A recent infrared study by Bamwenda et al. [7] revealed that the surface of a $\mathrm{Rh} /$ $\mathrm{Al}_{2} \mathrm{O}_{3}$ catalyst contained $\mathrm{NCO}$ and $\mathrm{CN}$ species during the selective reduction of NO by propylene. This is illustrative for a rather rich surface chemistry, allowing for several possible reaction pathways in which the formation of undesired products, such as $\mathrm{HCN}, \mathrm{HCNO}, \mathrm{NH}_{3}$ $[8,9]$ or even $\mathrm{NH}_{4} \mathrm{OCN}[10]$, is conceivable. Delouise and Winograd investigated the reactions between NO and carbon on $\mathrm{Rh}(331)$ by XPS and SIMS and detected a CN surface species in the temperature range between 400 and $800 \mathrm{~K}$ [11]. Harkness and Lambert recently reported on an electrochemical promotion effect of $\mathrm{Na}$ on the reaction between $\mathrm{NO}$ and $\mathrm{C}_{2} \mathrm{H}_{4}$ on $\mathrm{Pt}$, assigned to enhanced NO dissociation [12].

In this paper we use temperature programmed reac-

1 To whom correspondence should be addressed. tion spectroscopy (TPRS) and secondary ion mass spectrometry (SIMS) to explore the surface reactions between $\mathrm{NO}$ and $\mathrm{C}_{2} \mathrm{H}_{4}$ on rhodium (111). The adsorption of each of these gases separately on $\mathrm{Rh}(111)$ is well documented in work from several laboratories [13-16].

\section{Experimental}

The experiments were done in a UHV system (base pressure around $10^{-10}$ mbar) equipped with a Leybold SSM 200 quadrupole mass spectrometer for TPD and SSIMS measurements, as described in detail elsewhere [14]. The rhodium crystal, cut in the [111] orientation within $0.5^{\circ}$ and polished by standard procedures, was mounted on a moveable stainless steel manipulator with $0.3 \mathrm{~mm}$ thick tantalum wires, where it could be cooled to liquid nitrogen temperature and resistively heated up to $1500 \mathrm{~K}$. Temperatures were measured with a chromelalumel thermocouple spotwelded on the backside of the crystal. Small amounts of bulk impurities, such as sulphur, chlorine, and boron, were removed by cycli of argon sputtering $\left(1.5 \mathrm{keV}, 5 \mu \mathrm{A} / \mathrm{cm}^{2}\right)$ at $900 \mathrm{~K}$ and annealing to $1400 \mathrm{~K}$. Carbon was removed by annealing the crystal in $2 \times 10^{-8}$ mbar $\mathrm{O}_{2}$, by slowly varying the temperature between 900 and $1100 \mathrm{~K}$. Oxygen was removed from the surface by annealing shortly to $1425 \mathrm{~K}$. Ethylene (Messer Griesheim, 99.95\% pure) was used without further purification; gas exposures are reported in langmuir ( $\left.1 \mathrm{~L}=1.33 \times 10^{-6} \mathrm{mbar} \mathrm{s}\right)$; coverages are reported in monolayers (ML, number of adsorbates per $\mathrm{Rh}$ surface atom).

\section{Results and discussion}

First we briefly describe the most important characteristics of the adsorption and decomposition of ethylene 
and NO separately on Rh(111). Next follows a qualitative description of the reactions and surface species during heating of coadsorbed NO and ethylene on the basis of TPD and SIMS measurements. Finally, we discuss the influence of the amount of coadsorbed ethylene on the product distribution on the basis of oxygen and nitrogen mass balances.

\subsection{NOon $R h(111)$}

The dissociative adsorption of $\mathrm{NO}$ on $\mathrm{Rh}(111)$ and the selectivity towards formation of $\mathrm{N}_{2}$ are strongly affected by the extent to which the surface is occupied [13], Fig. la shows a few TPD spectra of characteristic cases. At low NO coverages (below 0.2 ML), all NO dissociates, and $\mathrm{N}_{2}$, labelled $\beta_{2}-\mathrm{N}_{2}$ is seen to desorb between 500 and $700 \mathrm{~K}$. SIMS measurements indicated that all NO dissociated already around room temperature, hence $\beta_{2}-\mathrm{N}_{2}$ evolution is a fully desorption limited process.

If the NO coverage is higher than about $0.2 \mathrm{ML}$, part of the NO desorbs, and $\mathrm{N}_{2}$ desorbs in two states, a low temperature state indicated as $\beta_{1}-N_{2}$, which shows firstorder desorption kinetics and comes just after the desorption of the NO, and the normal second-order desorption channel of $\beta_{2}-\mathrm{N}_{2}$, which, however, is strongly affected by repulsive interactions with $\mathrm{N}$ - and $\mathrm{O}$-atoms [13]. SIMS experiments showed that NO dissociation is retarded to temperatures where NO desorption takes place.

This coverage-dependent effect in the dissociation

a

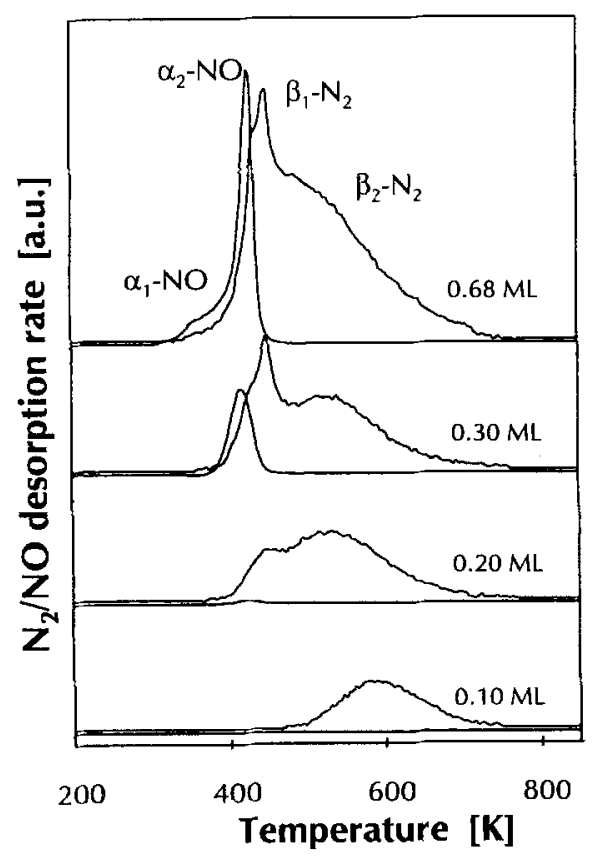

rate of NO has been attributed to an ensemble requirement of a dissociating NO molecule $[13,17]$. As a result, the dissociation at fully occupied surfaces is retarded to the temperatures where NO desorbs, after which dissociation of NO and desorption of $\beta_{1}-\mathrm{N}_{2}$ follow instantaneously.

\section{2. $\mathrm{C}_{2} \mathrm{H}_{4}$ on $\mathrm{Rh}(111)$}

Decomposition of olefins such as ethylene and propylene has extensively been studied on $\mathrm{Pt}$ and $\mathrm{Rh}$ [14 $16,18,19]$. In brief, ethylene adsorbs molecularly on rhodium at low temperatures, say around $120 \mathrm{~K}$, and at around $180 \mathrm{~K}$ it reacts to a species called ethylidyne, $\mathrm{CCH}_{3}$, and a $\mathrm{H}$-atom. Around $300 \mathrm{~K}$ the ethylidyne decomposes further to acetylide $(\mathrm{CCH}), \mathrm{CH}$ and carbidic C-atoms [19]. The decomposition reaction is retarded at higher coverages. Fig. $1 \mathrm{~b}$ shows the evolution of $\mathrm{H}_{2}$ during the decomposition. Up to $0.25 \mathrm{ML}$, all ethylene decomposes and $\mathrm{H}_{2}$ is the only product observed in the gas phase. At higher coverages, the excess ethylene desorbs, mainly at $180 \mathrm{~K}$ [14]. Note that at these higher coverages, hydrogen continues to be present in the form of $\mathrm{CH}_{x}$ species to temperatures as high as $700 \mathrm{~K}$, as fig. $1 \mathrm{~b}$ shows.

The conversion of ethylene to ethylidyne on $\mathrm{Rh}(111)$ has been followed in situ with static SIMS. For low coverages of ethylene (around $0.05 \mathrm{ML}$ ), evidence was found that the reaction proceeds through a vinyl $\left(-\mathrm{CH}=\mathrm{CH}_{2}\right)$ intermediate [14]. This in contrast to the situation on $\operatorname{Pt}(111)$, where ethylidene, $=\mathrm{CH}-\mathrm{CH}_{3}$, has

b

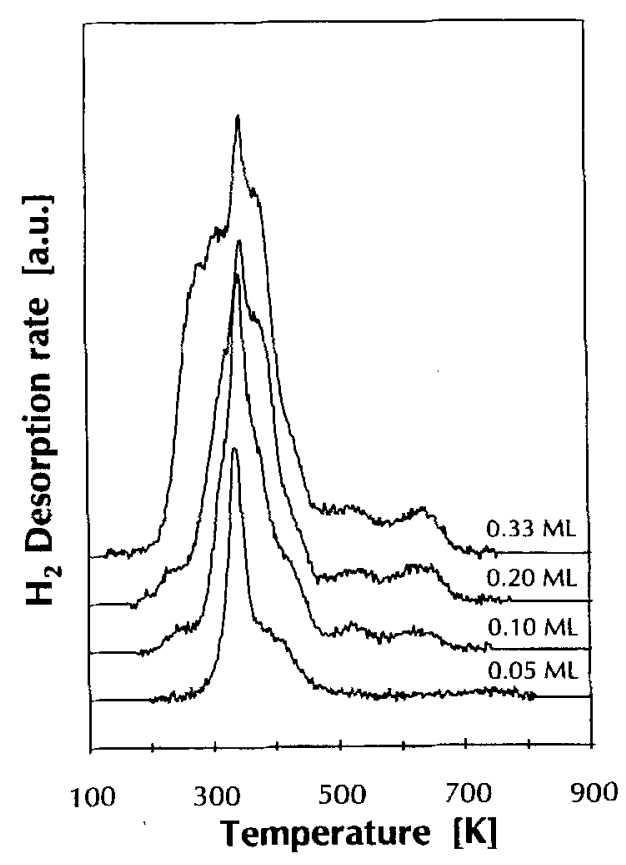

Fig. 1. (a) Temperature programmed desorption of $\mathrm{N}_{2}$ and NO from a Rh(111) surface covered with the indicated amounts of NO (heating rate $10 \mathrm{~K} / \mathrm{s}$ ), and (b) TPD of $\mathrm{H}_{2}$ from ethylene on $\mathrm{Rh}(111)$. The adsorption temperature was $100 \mathrm{~K}$, and the heating rate $5 \mathrm{~K} / \mathrm{s}$. 
been proposed as the intermediate towards ethylidyne [20].

\subsection{Coadsorption of NO and ethylene}

We now turn to coadsorbed $\mathrm{NO}$ and $\mathrm{C}_{2} \mathrm{H}_{4}$, and use the TPD/TPSIMS experiment performed on $0.20 \mathrm{ML}$ of NO coadsorbed with $0.12 \mathrm{ML}$ of ethylene in fig. 2 to illustrate qualitatively which reaction pathways occur.

The TPD spectra in the upper half of fig. 2 confirm that NO and ethylene not only react to the products that are desirable in the context of automotive exhaust catalysis, $\mathrm{N}_{2}, \mathrm{CO}_{2}$ and $\mathrm{H}_{2} \mathrm{O}$, but in addition one also observes significant amounts of $\mathrm{H}_{2}, \mathrm{NO}, \mathrm{CO}$, and $\mathrm{HCN}$. The signal at 28 amu can be due to three different molecules, ethylene, $\mathrm{CO}$ and $\mathrm{N}_{2}$. However, following the proper fragmentation signals at 12,14, 16 and $27 \mathrm{amu}$ enables one to distinguish between all three (and HCN, which also comes at $27 \mathrm{amu}$ ). It appears that ethylene does not desorb in this particular experiment, that the

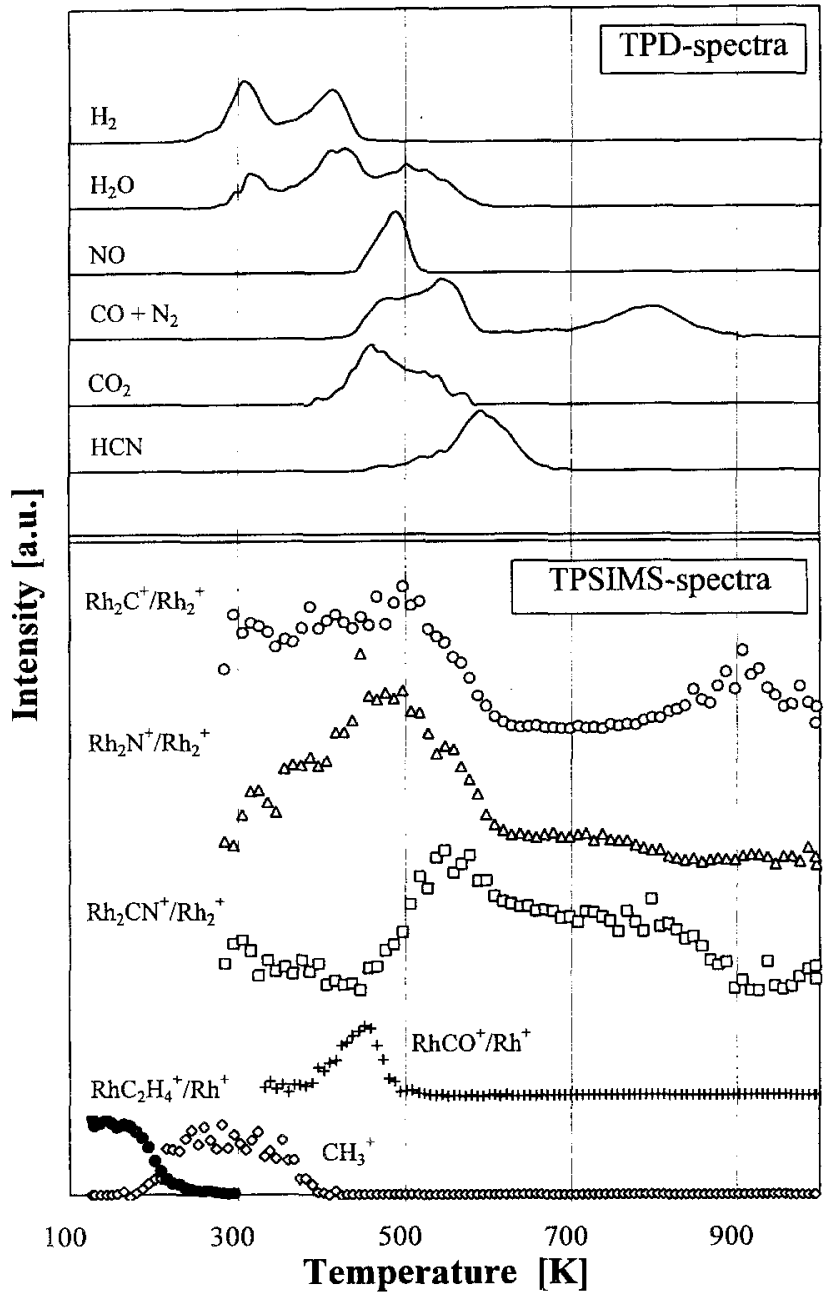

Fig. 2. Temperature programmed reactions of $0.12 \mathrm{ML}$ of ethylene coadsorbed with $0.20 \mathrm{ML}$ of NO as followed by TPD and SIMS (see text for explanation). The adsorption was done at $100 \mathrm{~K}$, and the heating rate was $10 \mathrm{~K} / \mathrm{s}$. peaks between 400 and $600 \mathrm{~K}$ are due to $\mathrm{CO}$ and that the peak above $700 \mathrm{~K}$ is caused by desorption of $\mathrm{N}_{2}$.

In order to obtain information on the processes occurring on the surface during heating, we have applied static SIMS, see the lower half of fig. 2. As the number of mass channels that can be measured simultaneously is limited, we only report a few characteristic secondary ions, such as $\mathrm{RhC}_{2} \mathrm{H}_{4}^{+}$representing molecularly adsorbed $\mathrm{C}_{2} \mathrm{H}_{4}, \mathrm{RhCO}^{+}$for adsorbed $\mathrm{CO}, \mathrm{Rh}_{2} \mathrm{C}^{+}$and $\mathrm{Rh}_{2} \mathrm{~N}^{+}$for adsorbed $\mathrm{C}$ - and $\mathrm{N}$-atoms, $\mathrm{Rh}_{2} \mathrm{CN}^{+}$for adsorbed cyanide groups, and $\mathrm{CH}_{3}^{+}$, which is characteristic for the ethylidyne species, $\mathrm{CCH}_{3}[14,21]$. In order to compensate at least partially for effects due to changes in work function during decompositions and reactions on the surface, it is customary to consider intensity ratios such as $\mathrm{RhC}_{2} \mathrm{H}_{4}^{+} / \mathrm{Rh}^{+}$, which often quite closely correlate with adsorbate coverage $[22,23]$.

At low temperature, both $\mathrm{NO}$ and $\mathrm{C}_{2} \mathrm{H}_{4}$ adsorb molecularly. The ethylene reveals itself in SIMS through a $\mathrm{RhC}_{2} \mathrm{H}_{4}^{+}$secondary ion. The first surface reaction that occurs during heating of $\mathrm{C}_{2} \mathrm{H}_{4}$ and $\mathrm{NO}$ is the conversion of ethylene to ethylidyne, $\mathrm{CCH}_{3}$, and $\mathrm{H}$-atoms, between 190 and $220 \mathrm{~K}$ [14]. The SIMS spectra in fig. 2 indicate the conversion of ethylene by a decrease of the $\mathrm{RhC}_{2} \mathrm{H}_{4}^{+}$ ratio and the accompanied formation of ethylidyne by the appearance of the methyl secondary ion, $\mathrm{CH}_{3}^{+}$. The $\mathrm{H}$-atoms formed in the ethylene $\rightarrow$ ethylidyne reaction start to desorb around $270 \mathrm{~K}$.

Just below $300 \mathrm{~K}$, NO dissociation sets in, as reflected by the growth of the $\mathrm{Rh}_{2} \mathrm{~N}^{+}$signal characteristic of $\mathrm{N}$ atoms, and the evolution of $\mathrm{H}_{2} \mathrm{O}$, which is reaction limited above $200 \mathrm{~K}$ on $\mathrm{Rh}(111)$ [24]. NO dissociation occurs in two steps, the first between roughly 300 and $350 \mathrm{~K}$, after which the $\mathrm{Rh}_{2} \mathrm{~N}^{+}$intensity reaches a short plateau, and the second above $400 \mathrm{~K}$, as can be inferred from a further rise in the $\mathrm{Rh}_{2} \mathrm{~N}^{+}$intensity and the appearance of additional peaks in the desorption of $\mathrm{CO}_{2}$ and $\mathrm{H}_{2} \mathrm{O}$, as we discuss in more detail below.

The decomposition of ethylidyne, seen by the decrease of the $\mathrm{CH}_{3}^{+}$intensity in SIMS, falls in the temperature range of approximately $300-380 \mathrm{~K}$, and is accompanied by the formation of $\mathrm{H}$-atoms, which either desorb as $\mathrm{H}_{2}$ or react with $\mathrm{O}$-atoms and a second $\mathrm{H}$-atom to $\mathrm{H}_{2} \mathrm{O}$, which desorbs instantaneously. $\mathrm{H}_{2}$ desorption terminates at about $450 \mathrm{~K}$. Note however that the surface still contains hydrogen - most probably present in the form of carbonaceous species - as $\mathrm{H}_{2} \mathrm{O}$ and $\mathrm{HCN}$ continue to desorb to almost 600 and $700 \mathrm{~K}$, respectively.

Oxidation of C-atoms appears to begin at $380 \mathrm{~K}$, as the growth of a $\mathrm{RhCO}^{+}$in SIMS, and the more or less simultaneous desorption of $\mathrm{CO}_{2}$ indicate. Apparently, the reaction between adsorbed $\mathrm{CO}$ and $\mathrm{O}$ is not sufficiently rapid to prevent the accumulation of $\mathrm{CO}$ on the surface. CO desorption is seen above $450 \mathrm{~K}$ both in TPD and in SIMS, in agreement with the literature of $\mathrm{CO}$ on $\mathrm{Rh}(111)[25,26]$. Also in this region, $450-520 \mathrm{~K}$, is the de- 
sorption of NO. Note that the desorption temperature of NO is significantly (i.e. about $70 \mathrm{~K}$ ) higher than if NO is the only adsorbate (fig. 1a). Following earlier work, we propose that this NO desorbs because the surface is to a large extent occupied, implying that the relatively large ensembles of free rhodium atoms necessary for NO dissociation are not available $[13,17]$. Hence, NO desorbs as soon as the temperature is high enough to permit this.

The SIMS data in fig. 2 strongly suggest that a large inventory of cyanide groups forms on the surface between 450 and $550 \mathrm{~K}$. First, the $\mathrm{Rh}_{2} \mathrm{CN}^{+}$intensity increases strongly and second, the intensities of both $\mathrm{Rh}_{2} \mathrm{~N}^{+}$and $\mathrm{Rh}_{2} \mathrm{C}^{+}$, characteristic of atomic nitrogen and carbon at these temperatures, decrease. Although the $\mathrm{Rh}_{2} \mathrm{C}^{+}$is observed as a fragment of adsorbed $\mathrm{C}_{2} \mathrm{H}_{x}$ species as well, it is very likely that all $\mathrm{C}-\mathrm{C}$ bonds have broken at the temperatures where $\mathrm{CN}$ groups start to form (i.e. $450 \mathrm{~K}$ ). The $\mathrm{Rh}_{2} \mathrm{~N}^{+}$intensity falls to a low value reflecting the fragmentation of $\mathrm{Rh}_{2} \mathrm{CN}^{+}$, while the $\mathrm{Rh}_{2} \mathrm{C}^{+}$falls practically to zero. Note that the observation of $\mathrm{CN}$ on the surface coincides with the onset of the $\mathrm{HCN}$ desorption and that $\mathrm{CN}$ formation occurs at higher temperatures than $\mathrm{CO}$ formation, reflecting that the reaction between carbon and oxygen is preferred above that between carbon and nitrogen atoms.

We do not believe that the cyanide is present as adsorbed HCN, because, first, the SIMS signal of the corresponding $\mathrm{Rh}_{2} \mathrm{HCN}^{+}$is not observed and second, the irregular leading edge of the HCN desorption trace suggests a reaction limited desorption process. Part of the cyanide inventory is hydrogenated to $\mathrm{HCN}$ between 500 and $650 \mathrm{~K}$, as seen by the desorption of $\mathrm{HCN}$ and the decrease in the $\mathrm{Rh}_{2} \mathrm{CN}^{+}$SIMS signal. Apparently, the adsorbate layer is fully dehydrogenated above $650 \mathrm{~K}$. The cyanide species remain stable until about $720 \mathrm{~K}$ where $\mathrm{N}_{2}$ desorption starts to occur, as evidenced by the $\mathrm{N}_{2}$ signal in TPD (accompanied by a parallel signal at 14 $\mathrm{amu}$ ), a decrease in the $\mathrm{Rh}_{2} \mathrm{CN}^{+}$signal in SIMS and an increase in the $\mathrm{Rh}_{2} \mathrm{C}^{+}$signal characteristic of adsorbed carbon. The $\mathrm{Rh}_{2} \mathrm{~N}^{+}$ion characteristic of adsorbed $\mathrm{N}$ atoms, is not observed, indicating that $\mathrm{N}_{2}$ desorbs instantaneously. The decrease of the $\mathrm{Rh}_{2} \mathrm{C}^{+}$signal above $900 \mathrm{~K}$ is attributed to the dissolution of carbon into the rhodium crystal [27].

\subsection{Coverage dependence}

Fig. 3 shows the evolution of the different desorbing gases as a function of increasing ethylene exposure for a fixed coverage of $0.20 \mathrm{ML}$ of $\mathrm{NO}$. The $\mathrm{H}_{2}$ TPD patterns start similarly as in the ethylene only case, with a desorption limited state at about $310 \mathrm{~K}$, which at low coverages is largely attributed to the recombinative desorption of $\mathrm{H}$-atoms formed at lower temperature $(180-220 \mathrm{~K})$ in the ethylene $\rightarrow$ ethylidyne conversion. The second peak growing in the range of $375-400 \mathrm{~K}$ is entirely attributed to reaction limited desorption of $\mathrm{H}_{2}$ originating from the decomposition of hydrocarbon fragments. Whereas $\mathrm{H}_{2}$ desorption continues up to $700 \mathrm{~K}$ for high coverages of ethylene in the absence of coadsorbed NO, it now stops at $450 \mathrm{~K}$.

Water desorption occurs in three distinct states. At all coverages, the water signal starts to grow at about $280 \mathrm{~K}$, which is the temperature where NO dissociation is known to begin [13]. Desorption of molecularly adsorbed water from $\mathrm{Rh}(111)$ occurs already between 150 and $220 \mathrm{~K}$, as reported by Wagner and Moylan [24]. The second state, with a peak maximum above $400 \mathrm{~K}$, parallels the second $\mathrm{H}_{2}$ desorption state and the second NO dissociation step (see fig. 2), and is due to recombinative desorption of $\mathrm{O}$-atoms with $\mathrm{H}$-atoms originating from the decomposition of $\mathrm{C}_{x} \mathrm{H}_{y}$ fragments on the surface. Note that the selectivity of the $\mathrm{H}$-atoms generated in this temperature interval (i.e. $350-450 \mathrm{~K}$ ) to form $\mathrm{H}_{2} \mathrm{O}$ is high at initially low ethylene coverage, and decreases when the H-content of the adsorbate layer increases, as expected. Interestingly, a third, reaction limited $\mathrm{H}_{2} \mathrm{O}$ desorption state develops around 500$540 \mathrm{~K}$, at high initial ethylene coverages. The intensity of this state parallels that of the NO desorption at somewhat lower temperature. We propose that the NO desorption between 450 and $520 \mathrm{~K}$ (which is significantly above the dissociation temperature of $\mathrm{NO}$ on the $\mathrm{Rh}$ (111) surface), together with the desorption of other gases such as $\mathrm{CO}$ and $\mathrm{CO}_{2}$, create space where additional NO dissociates, thus creating atomic oxygen giving rise to further $\mathrm{H}_{2} \mathrm{O}$ formation. As neither $\mathrm{H}$-atoms nor $\mathrm{OH}$ groups have a sufficiently long residence time on the surface at these temperatures, we propose that water formation between 500 and $600 \mathrm{~K}$ occurs by reactions such as $\mathrm{O}_{\mathrm{ads}}+\mathrm{CH}_{\mathrm{ads}} \rightarrow \mathrm{OH}_{\mathrm{ads}}+\mathrm{C}_{\mathrm{ads}}$, followed instantaneously by $\mathrm{OH}_{\mathrm{ads}}+\mathrm{CH}_{\mathrm{ads}} \rightarrow \mathrm{H}_{2} \mathrm{O}+\mathrm{C}_{\text {ads }}$.

The desorption of NO increases strongly with increasing total coverage, reflecting the ensemble requirement of the NO dissociation. It is interesting to note that the peak maximum temperature of $480-500 \mathrm{~K}$ is significantly higher than in the case of NO desorption from a $\mathrm{Rh}$ (111) surface occupied by NO only, which occurs at $430 \mathrm{~K}$ (see fig. 1a). In the latter case NO may be destabilized by repulsive lateral interactions with $N O, N$ and $O$, whereas in the present case NO desorbs out of an environment dominated by hydrocarbon fragments together with $\mathrm{CO}$, NO and $\mathrm{N}$, which apparently gives rise to reduced repulsion or possibly even attractive lateral interaction with the NO.

The mass 28 TPD spectra in fig. 3 are mainly due to $\mathrm{CO}$ and $\mathrm{N}_{2}$, and at high initial ethylene coverages probably also to $\mathrm{C}_{2} \mathrm{H}_{4}$. For intermediate coverages, one recognizes two $\mathrm{CO}$ desorption states with peak maximum temperatures of about 475 and $540-550 \mathrm{~K}$. The first is due to the desorption of adsorbed $\mathrm{CO}$, which formed on the surface between 400 and $475 \mathrm{~K}$ (see the $\mathrm{RhCO}^{+}$SIMS signal in fig. 2). The higher occurs almost 

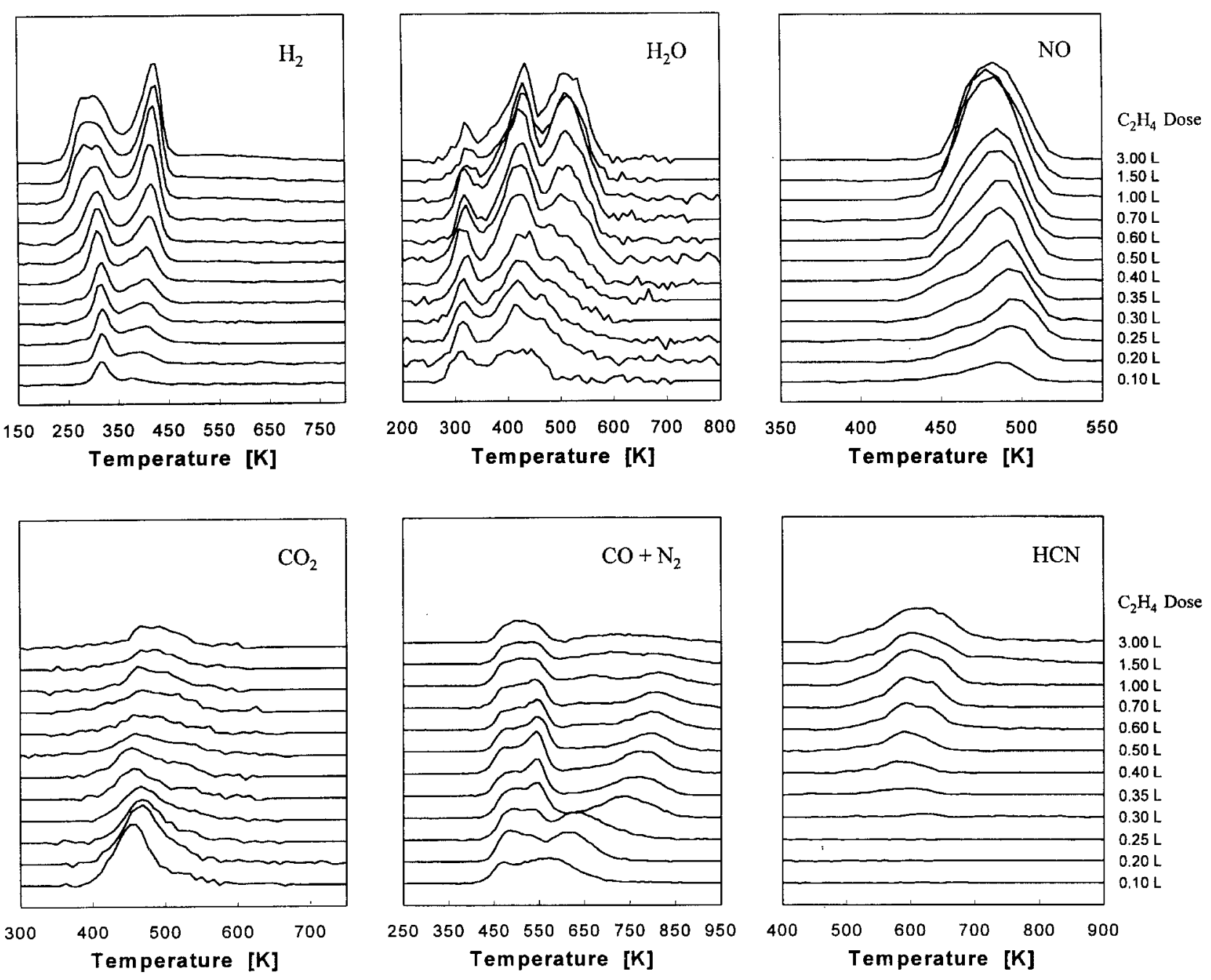

Fig. 3. TPD spectra of $0.20 \mathrm{ML}$ of NO, coadsorbed with varying amounts of ethylene on $\mathrm{Rh}(111)$, measured at a heating rate of $10 \mathrm{~K} / \mathrm{s}$. The adsorption temperature was $100 \mathrm{~K}$.

simultaneously with the third $\mathrm{H}_{2} \mathrm{O}$ desorption state and is attributed to the evolution of $\mathrm{O}$-atoms from additionally dissociating NO molecules at higher temperatures, as discussed above.

$\mathrm{CO}_{2}$ desorption is seen to commence significantly before $\mathrm{CO}$ desorbs, and parallels qualitatively the concentration of adsorbed $\mathrm{CO}$ as detected in SIMS (fig. 2). Hence, we conclude that $\mathrm{CO}_{2}$ desorption is favoured above desorption of $\mathrm{CO}$, but is limited by the availability of adsorbed O-atoms. This is in agreement with the dependence of the $\mathrm{CO}_{2}$ TPD intensities on both temperature and initial ethylene coverage.

The maximum of the $\mathrm{N}_{2}$ desorption shifts from $550-600 \mathrm{~K}$ at low to above $800 \mathrm{~K}$ for high initial ethylene coverage. We propose that the low temperature $\mathrm{N}_{2}$ desorption is due to recombinative desorption of atomic nitrogen, while the states at higher temperature reflect the decomposition of $\mathrm{CN}$ species in the range of $750-900 \mathrm{~K}$ (fig. 2), after which $\mathrm{N}$ atoms desorb instantaneously in a second-order process. The initial shift of the $\mathrm{N}_{2}$ desorption peak from $550-600 \mathrm{~K}$ upward when ethylene is coadsorbed in small amounts may well reflect the relieve of repulsive interactions by oxygen atoms that have been removed as $\mathrm{H}_{2} \mathrm{O}$ and $\mathrm{CO}_{2}$ or $\mathrm{CO}$ [13]. The further shift of the $\mathrm{N}_{2}$ signal to higher temperatures, however, is predominantly the effect of $\mathrm{CN}$ formation.

Finally, $\mathrm{HCN}$ desorption is observed at the higher initial ethylene coverages, i.e. above $0.30 \mathrm{~L} \mathrm{C}_{2} \mathrm{H}_{4}$ exposure. We take the irregularities in the desorption traces as an indication that $\mathrm{HCN}$ desorption is a reaction limited process. In principle there are two different reaction routes possible for HCN formation. The first one could be a direct coupling according to $\mathrm{CH}_{\mathrm{ads}}+\mathrm{N}_{\mathrm{ads}} \rightarrow \mathrm{HCN} \uparrow$. Secondly, HCN could also be formed by the hydrogenation of $\mathrm{CN}$ which has previously been formed by the reaction $\mathrm{C}_{\mathrm{ads}}+\mathrm{N}_{\mathrm{ads}} \rightarrow \mathrm{CN}_{\mathrm{ads}}$. In the latter case $\mathrm{HCN}$ formation is limited by the availability of $\mathrm{H}$-atoms, e.g. $\mathrm{CH}_{\mathrm{ads}} \rightarrow \mathrm{C}_{\mathrm{ads}}+\mathrm{H}_{\mathrm{ads}}$. It should be noted that if $\mathrm{HCN}$ formation proceeds according to the hydrogenation of $\mathrm{CN}$ by surface hydrogen, this process is highly favoured above $\mathrm{H}_{2}$ desorption since the latter is not observed. 


\subsection{O- and N-mass balances}

Fig. 4 shows the mass balances of nitrogen and oxygen, for a fixed coverage of $0.20 \mathrm{ML}$ of $\mathrm{NO}$ and $\mathrm{C}_{2} \mathrm{H}_{4}$ exposures of 0.20 and $0.70 \mathrm{~L}$, representing a low $(\sim 0.05 \mathrm{ML})$ and high $(\sim 0.17 \mathrm{ML})$ ethylene coverage situation, respectively. For the low coverage case of coadsorbed ethylene, nitrogen preferentially forms $\mathrm{N}_{2}$, and oxygen $\mathrm{CO}_{2}$ and $\mathrm{H}_{2} \mathrm{O}$. As the coverage of the "reducing agent" ethylene increases, one sees that the desired reduction of NO becomes increasingly less successful: The selectivity of nitrogen to leave the surface as $\mathrm{HCN}$ and $\mathrm{NO}$ increases and that of oxygen to form $\mathrm{CO}_{2}$ decreases significantly.

\section{Concluding remarks}

Temperature programmed reaction of $\mathrm{NO}$ and $\mathrm{C}_{2} \mathrm{H}_{4}$ produces a broad spectrum of products. At low $\mathrm{C}_{2} \mathrm{H}_{4}$ coverages, $\mathrm{H}_{2}, \mathrm{H}_{2} \mathrm{O}, \mathrm{CO}_{2}$ and $\mathrm{N}_{2}$ are the dominant products, but as the coverage increases, NO dissociation
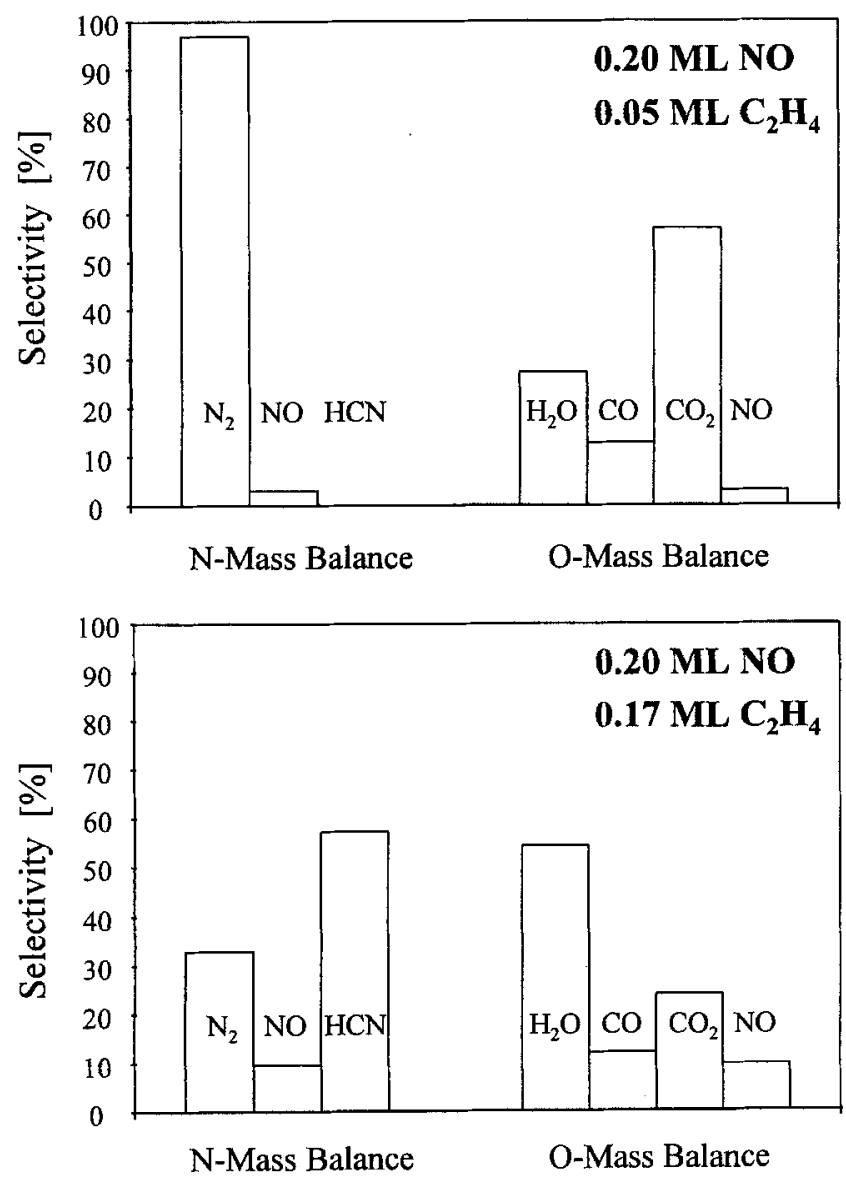

Fig. 4. $\mathrm{O}$ - and $\mathrm{N}$-mass balances showing the selectivities of $\mathrm{N}$ and $\mathrm{O}$ atoms from $0.20 \mathrm{ML}$ of $\mathrm{NO}$ on $\mathrm{Rh}(111)$ to desorb in the form of the indicated gases for a low $(\sim 0.05 \mathrm{ML})$ and a high $(\sim 0.17 \mathrm{ML})$ ethylene coverage case, obtained by exposing 0.20 and $0.70 \mathrm{~L} \mathrm{C}_{2} \mathrm{H}_{4}$, respectively. becomes hindered, and the fraction of NO that does dissociate has a relatively large probability to be trapped in an extensive reservoir of $\mathrm{CN}$ species, which forms between 450 and $550 \mathrm{~K}$. This is well above the NO dissociation temperature on occupied surfaces, and also above the temperature where the $\mathrm{C}-\mathrm{C}$ bond breaks, hence we conclude that neither NO dissociation nor $\mathrm{C}-\mathrm{C}$ bond scission are rate determining and that $\mathrm{CN}$ formation from adsorbed $\mathrm{C}$ and $\mathrm{N}$ atoms has an activation barrier which gives rise to a formation temperature above $450 \mathrm{~K}$. Depending on the availability of $\mathrm{H}$-atoms which are released from hydrocarbon fragments in the temperature range of 500-700 K, CN may be hydrogenated to gas phase $\mathrm{HCN}$. In the absence of hydrogen, the $\mathrm{CN}$ species are sufficiently stable to retard the desorption of $\mathrm{N}_{2}$ by some $200 \mathrm{~K}$ to the range of $650-850 \mathrm{~K}$.

Preliminary experiments on the reaction between adsorbed $\mathrm{N}$ atoms and ethylene have revealed that the selectivity for $\mathrm{N}$ to desorb as $\mathrm{HCN}$ may be close to $100 \%$ [28]. These experiments thus suggest that it should be possible to design a low temperature process for $\mathrm{HCN}$ formation starting from $\mathrm{NO}$ and ethylene.

\section{Acknowledgement}

This work was in part supported by the Netherlands Foundation for Chemical Research (SON) with financial aid from the Netherlands Organization for Scientific Research (NWO).

\section{References}

[1] K.C. Taylor, Catal. Rev. Sci. Eng. 35 (1993) 457.

[2] R. Impens, in: Catalysis and Automotive Pollution Control, eds. A. Crucq and A. Frennet (Elsevier, Amsterdam, 1987) p. 11.

[3] M. Iwamoto and H. Hamada, Catal. Today 10 (1991) 57.

[4] J.N. Armor, Catal. Today 26 (1995) 99, and references therein.

[5] A.P. Walker, Catal. Today 26(1995) 107.

[6] R. Burch and P.J. Millington, Catal. Today 26(1995) 185.

[7] G.R. Bamwenda, A. Obuchi, A. Ogata and K. Mizuno, Chem. Lett. (1994) 2109.

[8] C. Yokoyama and M. Misono, J. Catal. 150(1994) 9.

[9] F. Radtke, R.A. Köppel and A. Baiker, Catal. Today 26 (1995) 159.

[10] R.J.H. Voorhoeve, C.K.N. Patel, L.E. Trimble and R.J. Kerl, J. Catal. 54 (1978) 102.

[11] L.A. DeLouise and N. Winograd, Surf. Sci. 154 (1985) 79.

[12] I.A. Harkness and R.M. Lambert, J. Catal. 152(1995) 211.

[13] H.J. Borg, J.F.C.J.M. Reijerse, R.A. van Santen and J.W. Niemantsverdriet, J. Chem. Phys. 101 (1994) 10052.

[14] H.J. Borg, R.M. van Hardeveld, and J.W. Niemantsverdriet, J. Chem. Soc. Faraday Trans. 91 (1995) 3679.

[15] G.A. Somorjai, M.A. Van Hove and B.E. Bent, J. Phys. Chem. 92(1988) 973.

[16] L.H. Dubois, D.G. Castner and G.A. Somorjai, J. Chem. Phys. $72(1980) 5234$.

[17] R.A. van Santen and J.W. Niemantsverdriet, Chemical Kinetics and Catalysis (Plenum, New York, 1995).

[18] F. Zaera, J. Am. Chem. Soc. 111 (1989) 8744; Acc. Chem. Res. 25(1992) 260. 
[19] G.A. Somorjai, Introduction to Surface Chemistry and Catalysis (Wiley, New York, 1994).

[20] P. Cremer, C. Stanners, J.W. Niemantsverdriet, Y.R. Shen and G.A. Somorjai, Surf. Sci. 328 (1995) 111.

[21] J.R. Creighton and J.M. White, Surf. Sci. 129 (1983) 327.

[22] J.W. Niemantsverdriet, Spectroscopy in Catalysis (VCH, Weinheim, 1993)

[23] H.J. Borg and J.W. Niemantsverdriet, in: Catalysis, Specialist Periodical Report, Vol. 11, eds. J.J. Spivey and A.K. Agarwal (The Royal Society of Chemistry, Cambridge, 1994) p. 1.
[24] F.T. Wagner and T.E. Moylan, Surf. Sci. 191 (1987) 121.

[25] P.A. Thiel, J.T. Yates and W.H. Weinberg, Surf. Sci. 84 (1979) 54.

[26] L.H. Dubois and G.A. Somorjai, Surf. Sci. 91 (1980) 514.

[27] D.G. Castner and G.A. Somorjai, Surf. Sci. 83 (1979) 60.

[28] R.M. van Hardeveld, R.A. van Santen and J.W. Niemantsverdriet, in preparation. 